\title{
MERCURY LEVELS IN US CIIILDREN AND WOMEN
}

Data are presented from the 1999-2000 National Health and Nutrition Examination Survey (NHANES) on the distribution of blood mercury levels and association with fish consumption in a representative sample of young children and women of reproductive age. Household interviews, physical examinations, and blood mercury levels were performed on 705 children ( $56 \%$ response rate of selected participants) and 1709 ( $74 \%$ response rate). Blood mercury levels were 3 -fold higher in women than children. The mean concentration of total blood mercury was $0.34 \mathrm{mcg} / \mathrm{L}$ in children and $1.02 \mathrm{mcg} / \mathrm{L}$ in women. In women who ate 3 or more servings of fish in the past 30 days, the levels were 4 -fold higher than in those who ate no fish $(1.94 \mathrm{vs} 0.51 \mathrm{mcg} / \mathrm{L} ; \mathrm{p}<0.001)$. In children who ate fish, the levels were increased 2 -fold $(\mathrm{p}<0.001)$. Shellfish consumption had little effect on blood mercury levels in children, but women showed increased levels. Approximately $8 \%$ of women had mercury concentrations of $5.8 \mathrm{mcg} / \mathrm{L}$ or higher, representing exposures greater than those considered safe. (Schober SE, Sinks TH, Jones RL et al. Blood mercury levels in US children and women of childbearing age, 1999-2000. JAMA April 2 2003;289:1667-1674). (Reprints: Susan E Schrober PhD, National Center for Health Statistics, Centers for Disease Control and Prevention, 3311 Toledo Rd, Room 4210, Hyattsville, MD 20782).

COMMENT. Total blood mercury is indicative of methylmercury exposure in persons who consume fish and have no significant exposure to inorganic or elemental mercury. The persons in this study were considered unlikely to have been exposed to dental amalgams, thimerosol (ethyl mercury), or mercury preservatives. Urinary mercury is the preferred biomarker for low-level exposure to elemental and inorganic mercury. The American Heart Association recommends eating 2 servings of fish per week in adults. Most shellfish and some fish (haddock, tilapia, salmon, cod, and sole) are relatively low in methylmercury. See Progress in Pediatric Neurology III (PNB Publishers, 1997;pp515516) for reference to long-term effects of methylmercury poisoning in a New Mexico family after consuming contaminated pork. At 22 -year follow-up, 2 patients had cortical blindness, astereognosis, incoordination, ataxia, choreoathetosis, and attentional deficits. At autopsy, the brains showed cortical atrophy, neuronal loss and gliosis. Accidental exposure to mercury vapor is a hazard in nurseries with broken thermometers and in school science labs. Acrodynia (Pink disease) is a rare manifestation of mercury exposure in young children. Originally described in the 1950s, in infants who ingested calomelcontaining teething powders, the last case I saw personally, in 1962, involved a 3-year-old boy from Canada who had inhaled mercury vapor caused by spilling mercury on a floor radiator in the home. Erythema of face, fingertips and toes, weakness of all extremities, hyperesthesia, and extreme irritability are the main manifestations of acrodynia. 